\section{Acknowledgments.}

Financial support. No financial support was provided relevant to this article.

Conflicts of interest. All authors report no conflicts of interest relevant to this article.

\section{References}

1. CSSEGISandData/COVID-19. Github website. https://github.com/ CSSEGISandData/COVID-19. Accessed July 6, 2021.

2. COVID-19 vaccine for all above age of 18 years from May 1 ; states can buy vaccines directly from manufacturers. Times Now News website. https:// www.timesnownews.com/india/article/covid-19-vaccine-for-all-above-ageof-18-years-from-may-1-govt/747024. Published April 19, 2021. Accessed July 6, 2021.

3. Co-Win statistics. Indian Ministry of Health and Family Welfare website. cowin.gov.in. Accessed July 6, 2021.

4. How many people tested positive after second dose of Covid vaccine? Govt shares data. Mint website. https://www.livemint.com/news/india/how-manypeople-tested-positive-after-second-dose-of-covid-vaccine-govt-shares-data11619003508504.html. Published April 21, 2021. Accessed July 6, 2021.

5. Rise in demand for spike protein antibody tests among vaccine beneficiaries. Hindustan Times website. https://www.hindustantimes.com/cities/pune-news/ rise-in-demand-for-spike-protein-antibody-tests-among-vaccine-beneficiariesin-pune-101624035085417.html. Published June 19, 2021. Accessed July 6, 2021.

6. Mumbai: surge in spike protein antibody tests among vaccine beneficiaries. Hindustan Times website. https://www.hindustantimes.com/cities/ mumbai-news/mumbai-surge-in-spike-protein-antibody-tests-among-vac cine-beneficiaries-101621794783760.html. Published May 24, 2021. Accessed July 6, 2021.

7. Lucknow man alleges no antibodies developed after taking Covishield shot, files complaint against Adar Poonawalla, ICMR chief. The Economic Times website. https://economictimes.indiatimes.com/news/india/lucknow-man-alleges-noantibodies-developed-after-taking-covishield-shot-files-complaint-against-adarpoonawalla-icmr-chief/articleshow/83139314.cms. Published June 1, 2021. Accessed July 6, 2021.

8. What are spike proteins? News Medical Life Sciences website. https://www. news-medical.net/health/What-are-Spike-Proteins.aspx. Accessed July 6, 2021.

9. Antibody testing is not currently recommended to assess immunity after COVID-19 vaccination: FDA safety communication. US Food and Drug Administration website. https://www.fda.gov/medical-devices/safetycommunications/antibody-testing-not-currently-recommended-assessimmunity-after-covid-19-vaccination-fda-safety. Accessed July 6, 2021.

10. Interim clinical considerations for use of COVID-19 vaccines currently authorized in the United States. Centers for Disease Control and Prevention website. https://www.cdc.gov/vaccines/covid-19/clinical-considerations/covid19-vaccines-us.html?CDC_AA_refVal=https\%3A\%2F\%2Fwww.cdc.gov\%2F vaccines $\% 2$ Fcovid-19\%2Finfo-by-product $\% 2$ Fclinical-considerations. html. Accessed July 6, 2021.

11. Coronavirus FAQ: should I get my antibodies checked after I get vaccinated? National Public Radio website. https://www.npr.org/sections/goatsandsoda/ 2021/05/16/995446986/coronavirus-faq-should-i-get-my-antibodies-checkedafter-i-get-vaccinated. Published May 16, 2021. Accessed July 6, 2021.

\title{
The challenges of education in a continental country in the face of new severe acute respiratory coronavirus virus 2 (SARS-CoV-2) variant circulation
}

\author{
Henry Marcel Zalona Fernandes $\mathrm{MSc}^{1}$ (1), Karla Rodrigues Miranda $\mathrm{PhD}^{1}$ (1), Rubens Clayton da Silva Dias $\mathrm{PhD}^{2}$ (1), \\ Daniela Sales Alviano $\mathrm{PhD}^{1}$ (1), Rafael Silva Duarte MD, $\mathrm{PhD}^{1}$ (1) and Ana Carolina da Silva Carvalho $\mathrm{PhD}^{3}$ (1) \\ ${ }^{1}$ Institute of Microbiology, Federal University of Rio de Janeiro, Rio de Janeiro, Rio de Janeiro, Brazil, ${ }^{2}$ Biomedical Institute, Federal University of State of Rio de \\ Janeiro, Rio de Janeiro, Rio de Janeiro, Brazil and ${ }^{3}$ Institute of Chemistry, Federal University of Rio de Janeiro, Campus Macaé, Macaé, Rio de Janeiro, Brazil
}

To the Editor-On March 11, 2020, the World Health Organization (WHO) declared coronavirus disease 2019 (COVID-19) a global pandemic. To contain the spread of new coronavirus (SARS-CoV-2), several contact-restriction measures were adopted by different countries, such as home quarantine and school closures. ${ }^{1}$ According to the United Nations Educational, Scientific and Cultural Organization (UNESCO), Brazilian students were the most affected by the closing of schools compared to students from other countries. ${ }^{2,3}$ During the school closures, digital learning and other alternative educational strategies were implemented to avoid the academic regression of children and adolescents. However, home confinement and distance learning have caused psychological disorders for some students. At the same time, adequate communication between parents and

Author for correspondence: Henry Marcel Zalona Fernandes, E-mail: henry_zalona@ hotmail.com

Cite this article: Zalona Fernandes HM, et al. (2022). The challenges of education in a continental country in the face of new severe acute respiratory coronavirus virus 2 (SARSCoV-2) variant circulation. Infection Control \& Hospital Epidemiology, 43: 1537-1539, https://doi.org/10.1017/ice.2021.291 children can play a protective role against mental health disorders in students. ${ }^{1}$ Nevertheless, the return to face-to-face education is essential to reduce the harms resulting from digital exclusion, interruption of physical activities, the preclusion of social interaction, and other factors. ${ }^{4}$

The appropriate moment for schools to reopen should be assessed according to local epidemiological data. Cities with low prevalence rates and effective measures to mitigate SARS-CoV-2 transmission have not reported significant pediatric outbreaks. However, the main pediatric outbreaks have occurred in communities with less stringent mitigation measures and widespread SARS-CoV-2 transmission., ${ }^{5,}$ Pediatric patients affected by COVID-19 may be asymptomatic or may present with mild respiratory symptoms. The expression of angiotensin-converting enzyme 2 (ACE-2) in the nasal epithelium is age related, so the lower expression in pediatric patients is the probable reason for symptoms rarely involving the lower respiratory tract and loss of smell and taste, as occurs in adult patients. In addition, pediatric patients can also present with multisystemic inflammatory 
Table 1. Distribution of Different SARS-CoV-2 Lineages Identified in the Brazilian States

\begin{tabular}{|c|c|c|c|}
\hline Region & State & SARS-CoV-2 Lineages & Total \\
\hline \multirow[t]{7}{*}{ North } & Acre & B.1.1, B.1.1.33, B.1.212 & 3 \\
\hline & Amapá & B.1.1.33, B.1.160.25, N.10, P.1, P.2 & 5 \\
\hline & Amazonas & $\begin{array}{l}\text { A.2, B.1, B.1.1, B.1.1.117, B.1.1.218, B.1.1.28, B.1.1.33, B.1.1.34, B.1.1.378, B.1.111, B.1.195, B.1.212, B.1.319, } \\
\text { B.1.566, N.9, P.1, P.1.1, P.2 }\end{array}$ & 18 \\
\hline & Pará & B.1, B.1.1, B.1.1.1, B.1.1.28, B.1.1.33, B.1.212, B.1.395, B.39, N.9, P.1, P.2 & 11 \\
\hline & Rondônia & B.1.1.28, B.1.1.33, B.1.212, N.9, P.1, P.2 & 6 \\
\hline & Roraima & B.1, B.1.1.33, P.1 & 3 \\
\hline & Tocantins & B.1, B.1.1, B.1.1.28, B.1.1.33, P.1, P.2 & 6 \\
\hline \multirow[t]{9}{*}{ Northeast } & Alagoas & B.1.1, B.1.1.143, B.1.1.28, B.1.1.29, B.1.1.33, B.1.1.34, B.1.1.371, B.1.1.372, B.1.1.7, N.9, P.1, P.2 & 12 \\
\hline & Bahia & $\begin{array}{l}\text { A.1, B.1, B.1.1, B.1.1.106, B.1.1.141, B.1.1.162, B.1.1.180, B.1.1.28, B.1.1.29, B.1.1.314, B.1.1.33, B.1.1.333, B.1.1.34, } \\
\text { B.1.1.7, B.1.167, B.1.525, B.1.610, B.3, C.14, N.4, N.9, P.1, P.2 }\end{array}$ & 20 \\
\hline & Ceará & B, B.1, B.1.1, B.1.1.143, B.1.1.28, B.1.1.282, B.1.1.33, B.1.1.34, B.1.1.44, B.1.212, N.9, P.1, P.2 & 13 \\
\hline & Maranhão & B.1.1, B.1.1.28, B.1.1.33, B.1.1.332, B.1.234, N.10, N.9, P.1, P.2 & 9 \\
\hline & Paraíba & $\begin{array}{l}\text { B.1, B.1.1, B.1.1.141, B.1.1.143, B.1.1.232, B.1.1.269, B.1.1.28, B.1.1.29, B.1.1.33, B.1.1.34, B.1.1.462, B.1.212, N.9, } \\
\text { P.1, P.2 }\end{array}$ & 15 \\
\hline & Pernambuco & $\begin{array}{l}\text { B, B.1, B.1.1, B.1.1.10, B.1.1.117, B.1.1.139, B.1.1.15, B.1.1.192, B.1.1.28, B.1.1.29, B.1.1.208, B.1.1.227, B.1.1.314, } \\
\text { B.1.1.33, B.1.1.34, B.1.1.74, B.1.1.94, B.1.212, B.1.258, N.9, P.2 }\end{array}$ & 21 \\
\hline & Piauí & B.1.1.33, N.9 & 2 \\
\hline & Rio Grande do Norte & B.1.1, B.1.1.28, B.1.1.33, B.1.195, N.9, P.1, P.2 & 7 \\
\hline & Sergipe & B.1, B.1.1, B.1.1.28, B.1.1.29, B.1.1.33, B.1.1.7, B.1.212, B.1.610, B.59, N.9, P.1, P.2 & 12 \\
\hline \multirow[t]{4}{*}{ Mid West } & Distrito Federal & B, B.1, B.1.1, B.1.1.28, B.1.1.33, B.1.1.7, B.1.177.32, P.1, P.2 & 9 \\
\hline & Goiás & B.1, B.1.1.28, B.1.1.29, B.1.1.33, B.1.1.7, B.1.22, B.40, P.1, P.2 & 9 \\
\hline & Mato Grosso & B.1.1.28, B.1.1.33, B.1.1.7, B.4 & 4 \\
\hline & Mato Grosso do Sul & B.1, B.1.1, B.1.1.28, B.1.1.33, B.1.1.7, B.1.212, B.1.240, B.1.547, N.4, P.1, P.2 & 11 \\
\hline \multirow[t]{4}{*}{ Southeast } & Espírito Santo & B.1, B.1.1, B.1.1.143, B.1.1.28, B.1.1.33, B.1.1.7, B.40, P.1, P.2 & 9 \\
\hline & Minas Gerais & $\begin{array}{l}\text { B, B.1, B.1.1, B.1.1.143, B.1.1.190, B.1.1.218, B.1.1.28, B.1.1.33, B.1.1.372, B.1.1.7, B.1.1.71, B.1.153, B.1.177, B.1.2, } \\
\text { B.1.212, B.1.234, B.1.235, B.1.314, B.1.36.10, B.1.408, B.1.526.1, B.1.9, B.59, B.61, P.1, P.2 }\end{array}$ & 26 \\
\hline & Rio de Janeiro & $\begin{array}{l}\text { A.2, B.1, B.1.1, B.1.1.109, B.1.1.143, B.1.1.218, B.1.1.222, B.1.1.277, B.1.1.28, B.1.1.29, B.1.1.306, B.1.1.31, B.1.1.314, } \\
\text { B.1.1.33, B.1.1.393, B.1.1.7, B.1.1.94, B.1.111, B.1.153, B.1.167, B.1.222, B.1.398, B.1.422, B.1.565, B.1.577, B.1.582, } \\
\text { B.1.596, B.39, N.1, N.4, N.9, P.1, P.2 }\end{array}$ & 33 \\
\hline & São Paulo & $\begin{array}{l}\text { A, B, B.1, B.1.1, B.1.1.1, B.1.1.143, B.1.1.208, B.1.1.28, B.1.1.318, B.1.1.33, B.1.1.332, B.1.1.333, B.1.1.378, B.1.1.393, } \\
\text { B.1.1.464, B.1.1.519, B.1.1.7, B.1.177.52, B.1.195, B.1.212, B.1.221, B.1.234, B.1.351, B.1.446, B.1.566, B.23, B.3, B.40, } \\
\text { B.6, N.9, P.1, P.1.1, P.2 }\end{array}$ & 33 \\
\hline \multirow[t]{3}{*}{ South } & Paraná & $\begin{array}{l}\text { A, B.1, B.1.1, B.1.1.1, B.1.1.143, B.1.1.250, B.1.1.28, B.1.1.29, B.1.1.33, B.1.1.7, B.1.195, B.1.375, B.1.498, B.1.98, P.1, } \\
\text { P.1.1, P.2 }\end{array}$ & 17 \\
\hline & Rio Grande do Sul & $\begin{array}{l}\text { A, B, B.1, B.1.1, B.1.1.143, B.1.1.28, B.1.1.29, B.1.1.33, B.1.1.332, B.1.1.7, B.1.1.70, B.1.177, B.1.195, B.1.212, B.1.416, } \\
\text { B.1.575, B.1.91, P.1, P.2 }\end{array}$ & 19 \\
\hline & Santa Catarina & B.1, B.1.1, B.1.1.1, B.1.1.143, B.1.1.279, B.1.1.28, B.1.1.33, B.1.1.332, B.1.1.7, B.1.195, B.6, N.9, P.1, P.2 & 14 \\
\hline
\end{tabular}

syndrome (MIS-C), a life-threatening disease, similar to toxic shock syndrome and Kawasaki disease. MIS-C is predominantly reported among children of Black and/or Latino ancestry. Thus, schools reopening in Africa and Latin America countries may generate epidemic patterns that differ from those on other continents, especially during the high local circulation of SARS-CoV-2. For example, more transmissible variants have emerged in Brazil (P.1 lineage) and South Africa (B.1.351 lineage)., ${ }^{46}$

In 2020, researchers verified high rates of SARS-CoV-2 infection by B.1.195 and B.1.1.28 lineages, with subsequent seroconversion in the population of Manaus, Brazil. However, the P.1 lineage, a variant with mutations related to increased transmissibility, ACE-2 affinity, and antibody evasion, resulted in outbreaks and COVID-19 recurrence in Manaus during January 2021, spreading throughout the country thereafter, including municipalities bordering Peru, Colombia, and Venezuela. Hence, the genetic, immunological, and epidemiological characteristics of new SARS-CoV-2 lineages should be monitored regionally, and the clinical risk for new patients should be assessed, especially in grouping situations, such as children in classrooms. ${ }^{7}$ The emergence and dissemination of new variants occur due to epidemiological factors, such as the lack of efficient social distancing, contributing to the occurrence of pediatric outbreaks, increased hospitalizations and bed occupations. ${ }^{6,7}$ Recently, the Oswaldo 
Cruz Foundation (FIOCRUZ) Genomics Network reported the presence of 110 SARS-CoV-2 lineages in Brazilian states, including highly transmissible lineages related to outbreaks and more severe cases of COVID-19. This finding reinforces the genomic surveillance need to properly manage the COVID-19 pandemic in Brazil (Table 1). ${ }^{8}$

The ethnic diversity and socioeconomic inequalities present in Brazil also determine the epidemiology of COVID-19. Although studies performed in developed countries have determined that the spread and worsening of COVID-19 among children have low significance, regional differences have been observed among Brazilian children and adolescents with COVID-19 such as higher mortality in less socioeconomically developed municipalities, especially in the northern region of Brazil. Furthermore, individuals with 2 or more comorbidities may have 9.6-fold increased risk of death from COVID-19., ${ }^{4,9}$ Another Brazilian study analyzed patients aged $<19$ years infected with SARS-CoV-2 in the state of Sergipe, Northeastern Brazil, and verified that the mortality rate was 37-fold higher than that reported in the United States and the United Kingdom. This unusual and high mortality rate increases with the local absence of pediatric intensive care unit (ICU) beds and the presence of comorbidities, such as neurological diseases and prematurity. ${ }^{10}$ To avoid COVID-19 and subsequent pediatric hospitalizations with the return of face-to-face classes, appropriate mitigation measures are necessary.

The main strategies in health protocols for preventing the COVID-19 spread in face-to-face classes are mask wearing, sanitization of hands, surface disinfection, guidance for home quarantine of students or employees with a positive test for SARS-CoV-2, and adjustment of infrastructure in schools. ${ }^{4}$ On the other hand, the scarce resources invested in Brazilian public education in recent years have placed these educational institutions in very precarious conditions, increasing social inequalities. The average amount spent per student in Brazil is half that spent by Brazilian private schools and countries of the Organization for Economic Co-operation and Development (OECD). In addition, the adverse economic effects caused by the COVID-19 pandemic have also resulted in reduced resources for basic education, as seen in countries with an educational financing system similar to the Brazilian system. Thus, the lack of basic infrastructure in Brazilian public schools represents an obstacle to the necessary adaptations to prevent the spread of SARS-CoV-2 among students and staff. ${ }^{2}$

Therefore, the elaboration and execution of health protocols for the schools reopening during the pandemic should be supported by real data representative of each region and Brazilian context because socioeconomic vulnerabilities and comorbidities are risk factors for the worsening of COVID-19 rates among Brazilian children. As long as no COVID-19 vaccination or treatment is available for children, the return to face-to-face classes places Brazilian students at higher risk for COVID-19 due to the national circulation of highly transmissible SARS-CoV-2 lineages and the lack of hospital beds in low-income regions of the country.

Acknowledgments.

Financial support. This study was supported by the Coordenação de Aperfeiçoamento de Pessoal de Nível Superior of Brazil (CAPES; finance code 001).

Conflicts of interest. All authors report no conflicts of interest relevant to this article.

\section{References}

1. Tang S, Xiang M, Cheung T, Xiang YT. Mental health and its correlates among children and adolescents during COVID-19 school closure: the importance of parent-child discussion. J Affect Disord 2021;279:353-360.

2. Alves T, Farenzena N, Silveira AAD, Pinto JMDR. Implications of the COVID-19 pandemic on funding basic education. Rev de Adm Pública 2020;54:979-993.

3. COVID-19 impact on education. Global monitoring of school closures. UNESCO website. https://en.unesco.org/covid19/educationresponse. Accessed May 31, 2021.

4. Esposito S, Zona S, Vergine G, et al. How to manage children if a second wave of COVID-19 occurs. Int J Tuberc Lung Dis 2020;24:1116-1118.

5. Lee B, Raszka WV. COVID-19 in children: looking forward, not back. Pediatrics 2021;147:e2020029736.

6. Parcha V, Booker KS, Kalra R, Kuranz S, Berra L, Arora G, Arora P. A retrospective cohort study of 12,306 pediatric COVID-19 patients in the United States. Sci Rep 2021;11:1-10.

7. Naveca FG, Nascimento V, de Souza VC. COVID-19 in Amazonas, Brazil, was driven by the persistence of endemic lineages and P. 1 emergence. Nat Med 2021. doi: 10.1038/s41591-021-01378-7.

8. Tabelas de dados demonstrativos de linhagens e genomas SARS-CoV-2. FIOCRUZ Genomics Network website. http://www.genomahcov.fiocruz. br/tabela-de-dados/. Accessed May 31, 2021.

9. Sousa BLA, Brentani AVM, Ribeiro CCC, et al. Noncommunicable diseases, sociodemographic vulnerability, and the risk of mortality in hospitalized children and adolescents with COVID-19 in Brazil: a syndemic in play. medRxiv 2021. doi: 10.1101/2021.02.11.21251591.

10. Lopes ASA, Vieira SCF, Porto RLS, et al. Coronavirus disease-19 deaths among children and adolescents in an area of Northeast Brazil: why so many? Trop Med Int Health 2021;26:115-119. 